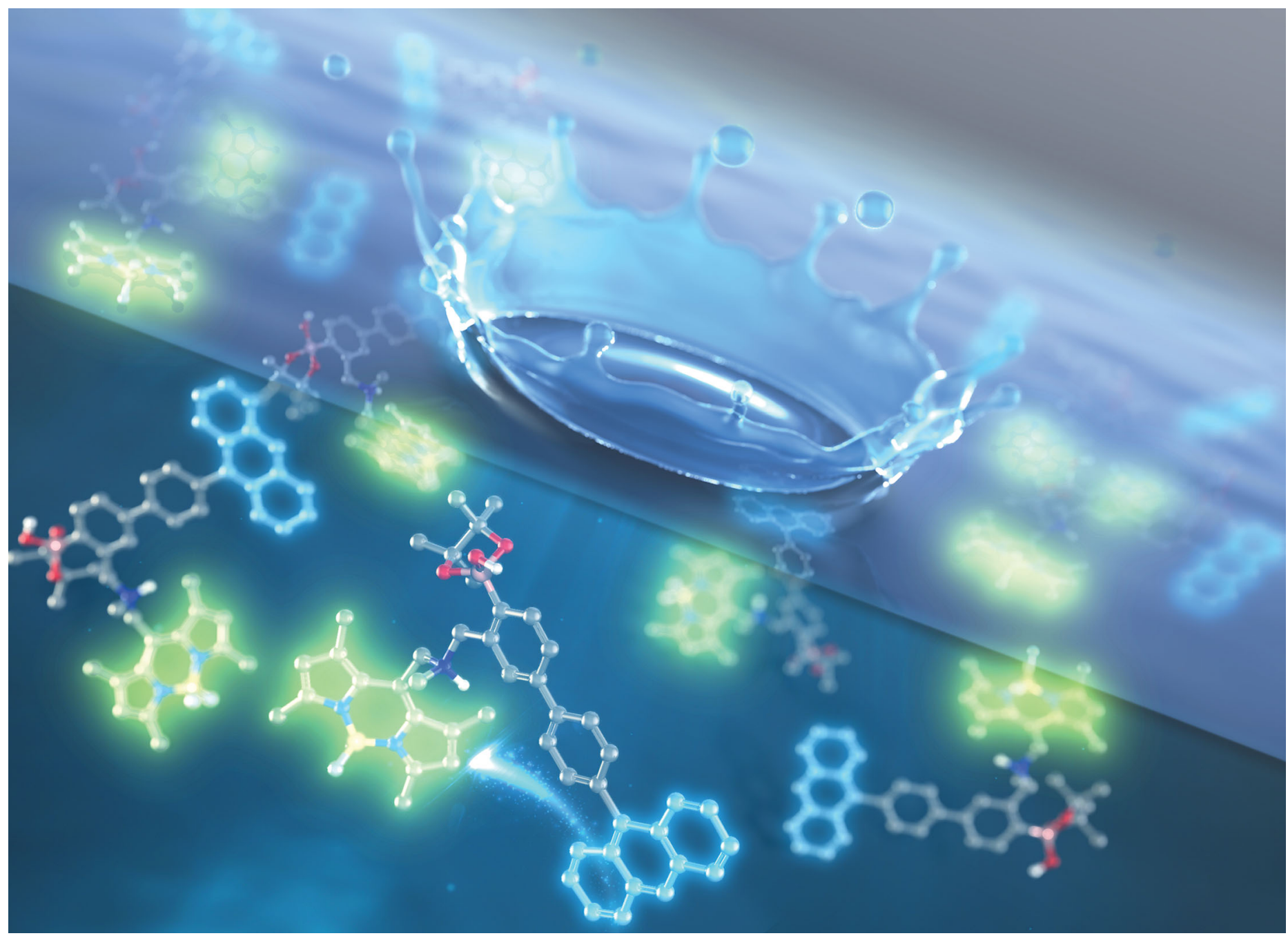

Showcasing research from Professor Yousuke Ooyama's Functional Dye Chemistry laboratory, Department of Applied Chemistry, Graduate School of Engineering, Hiroshima University, Japan

Development of fluorescent sensors based on a combination of PET (photo-induced electron transfer) and FRET (Förster resonance energy transfer) for detection of water

The optical method utilizing fluorescent sensors for the determination of water content allows the visualization, detection and quantification of water content in samples based on the changes in wavelength, intensity and lifetime of photoluminescence depending on the water content. The PET/FRET-based fluorescent sensors for water have been designed and developed, and this work demonstrated that a combination of a PET-type donor fluorophore and an acceptor fluorophore in the FRET process is one of the most promising molecular designs to create an efficient fluorescent sensor for the detection of water in organic solvents.
As featured in:

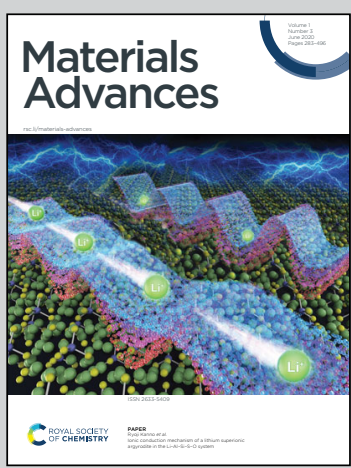

See Yousuke Ooyama et al., Mater. Adv., 2020, 1, 354 
Check for updates

Cite this: Mater. Adv., 2020 1,354

Received 28th March 2020, Accepted 12th May 2020

DOI: $10.1039 / \mathrm{d} 0 \mathrm{ma00139b}$

rsc.li/materials-advances

\section{Development of fluorescent sensors based on a combination of PET (photo-induced electron transfer) and FRET (Förster resonance energy transfer) for detection of water $\dagger$}

\author{
Daisuke Jinbo, Kazuki Ohira, Keiichi Imato (D) and Yousuke Ooyama (D)*
}

\begin{abstract}
Fluorescent sensors DJ-1 and DJ-2 with a large Stokes shift (SS) based on a combination of PET (photoinduced electron transfer) and FRET (Förster resonance energy transfer) have been developed for the detection of water in organic solvents. DJ-1 is composed of anthracene-(aminomethyl)phenylboronic acid ester as the PET-type donor fluorophore and a BODIPY skeleton as the acceptor fluorophore in the FRET process. In contrast, DJ-2 is composed of an anthracene skeleton as the donor fluorophore and a BODIPY-(aminomethyl)phenylboronic acid ester skeleton as the PET-type acceptor fluorophore in the FRET process. In fact, the addition of water to organic solvents containing DJ-1 or DJ-2 caused both PET suppression and energy transfer from the donor fluorophore to the acceptor fluorophore through the FRET process, thus resulting in an enhancement of the fluorescence band originating from the BODIPY skeleton. In addition, the pseudo-SS values of DJ-1 and DJ-2 between the photoabsorption maximum of the anthracene fluorophore and the fluorescence maximum of the BODIPY fluorophore are $7563 \mathrm{~cm}^{-1}(141 \mathrm{~nm})$ and $8017 \mathrm{~cm}^{-1}(153 \mathrm{~nm})$, respectively, which are significantly higher than those of a typical PET-based fluorescent sensor. It was found that the FRET efficiency for DJ-1 is quantitative, but that for DJ-2 was estimated to be ca. $50 \%$ based on time-resolved fluorescence lifetime measurements. Moreover, the detection limit of DJ-1 for water is superior to that of DJ-2. Based on the fluorescence sensing mechanism of DJ-1 and DJ-2 for water, we propose that a combination of a PETtype donor fluorophore and an acceptor fluorophore in the FRET process is one of the most promising molecular designs to create an efficient fluorescent sensor for the detection of water in organic solvents.
\end{abstract}

\section{Introduction}

The visualization as well as detection and quantification of water in samples and products, such as solutions, solids, and gas or water on the surface of a substrate, are doubtless significant in not only fundamental study in photochemistry, photophysics and analytical chemistry, but also their potential applications to environmental and quality control monitoring systems and industry. ${ }^{1,2}$ As a common and classical method for the determination of water content, the Karl Fischer titration method, which utilizes coulometric or volumetric titration to determine the amount of water (0.001-100 wt\%) in a sample such as a solution or solid, is widely used in the laboratory and industry. Coulometric titration is suitable for the determination of a low amount of water below $0.1 \mathrm{wt} \%$ and it is based on the

Department of Applied Chemistry, Graduate School of Engineering,

Hiroshima University, 1-4-1 Kagamiyama, Higashi-Hiroshima 739-8527, Japan.

E-mail: yooyama@hiroshima-u.ac.jp; Fax: +81 82-424-5494

$\dagger$ Electronic supplementary information (ESI) available. See DOI: 10.1039/d0ma00139b
Karl Fischer reaction (eqn (1) $\mathrm{I}_{2}+\mathrm{SO}_{2}+3$ Base $+\mathrm{ROH}+\mathrm{H}_{2} \mathrm{O} \rightarrow$ $2 \mathrm{Base} \cdot \mathrm{HI}+$ Base $\cdot \mathrm{HSO}_{4} \mathrm{R}$ and eqn (2) $2 \mathrm{I}^{-}-2 \mathrm{e}^{-} \rightarrow \mathrm{I}_{2}$ ), that is, 1 mole of water will react with 1 mole of iodine generated electrolytically by eqn (2), so that the electricity for 1 milligram of water is equivalent to 10.71 coulombs. Therefore, the Karl Fischer titration method has sufficient accuracy, but it is a batch (ex situ) analysis process, which leads to time-consuming measurements as well as the inability of real-time monitoring and flow (in situ) analysis of the water content. On the other hand, the optical method utilizing colorimetric and fluorescent sensors for the determination of water content has become of considerable scientific and practical concern in recent years, because it allows the visualization, detection and quantification of water content in samples and products using a highly sensitive and quick flow analysis based on the changes in wavelength, intensity and lifetime of photoabsorption and photoluminescence depending on the water content. In fact, to date, some kinds of organic fluorescent sensors and polymers for the determination of water content based on ICT (intramolecular charge transfer), ${ }^{3,4}$ PET (photo-induced electron transfer), ${ }^{5,6}$ 
ESIP (excited state intramolecular proton transfer), ${ }^{7}$ or solvatochromic properties ${ }^{8}$ have been designed and synthesized. The optical sensing properties of these fluorescent sensors for the detection and quantification of water content were investigated from the viewpoints of the relationship between ICT, PET, or ESIP characteristics and the intermolecular interaction of the sensor with water molecules. As a result, it was found that most of the previous fluorescent sensors for water content determination, including conjugated polymers and organic fluorescent dyes with ICT and ESIP characteristics, are based on a fluorescence quenching (turn-off) system, that is, the fluorescence intensity of the sensor decreases as a function of water content in organic solvents. However, this fluorescence quenching system makes it difficult to detect a trace amount of water. In contrast, a fluorescence enhancement (turn-on) system exhibiting a fluorescence response with an increase in water content in organic solvents is useful for the visualization, detection and quantification of a trace amount of water in organic solvents. For example, chemodosimeters ${ }^{9}$ based on water-triggered reactions such as Schiff base hydrolysis and spiro-ring opening reactions, and PET-type fluorescent sensors ${ }^{5,6}$ based on the suppression of PET from the electron donor part to the photoexcited fluorophore due to the intermolecular interactions between the fluorescent sensor and water molecules belong to the fluorescence enhancement systems for determination of low water content. On the other hand, AIEE (aggregation-induced emission enhancement) of organic fluorophores in the aggregation state has been reported as a fluorescence enhancement system for high water content, that is, an AIEE dye such as tetraphenylethene (TPE) and its derivatives exhibits emission enhancement due to the restricted intramolecular rotation (RIR) in the molecular structures induced by aggregate formation upon addition of large amounts of water (over $40 \mathrm{wt} \%$ in almost every case) into the solution. ${ }^{10}$ In particular, the fluorescence enhancement system based on the PET-type fluorescent sensor for water can detect a reversible change in its immediate environment due to the reversible intermolecular interactions between the sensor and water molecules. Actually, in our previous work, anthracene-(aminomethyl)phenylboronic acid pinacol esters (OM-1, OF-1 and OF-2 $)^{6 d}$ and BODIPY(aminomethyl)phenylboronic acid ester (MH-1) ${ }^{6 f}$ were designed and synthesized as PET-based fluorescent sensors for the determination of a trace amount of water (Fig. 1a and b). The PET takes place from the nitrogen atom of the amino moiety to the photoexcited fluorophore skeleton in the absence of water, leading to fluorescence quenching. The addition of water to organic solvents containing the PET-based fluorescent sensor causes a drastic and linear enhancement of fluorescence emission as a function of water content, which is attributed to the suppression of PET. The nitrogen atom of the amino moiety is protonated or strongly interacts with water molecules, leading to the formation of the PET inactive species such as OM-1a. Thus, the PET method makes it possible to visualize, detect and determine a trace amount of water in organic solvents. However, the PET-based fluorescent sensor usually has the disadvantage of a very small Stokes shift (SS), causing serious self-quenching and fluorescence detection errors due to photoexcitation and scattering light from

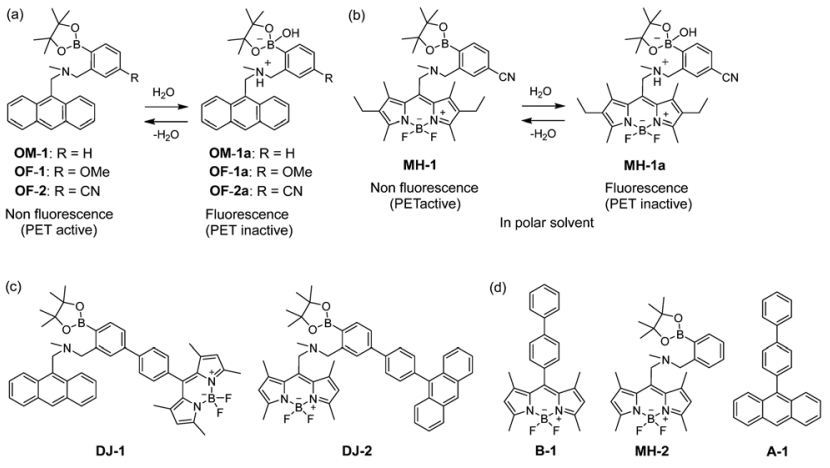

Fig. 1 Proposed mechanisms of PET-type fluorescent sensors (a) OM-1, OF-1, OF-2 and (b) MH-1 for the detection of water in a solvent. Chemical structures of (c) PET/FRET-type fluorescent sensors DJ-1 and DJ-2, (d) BODIPY derivative B-1, PET-type BODIPY $\mathbf{M H - 2}$ and anthracene derivative A-1.

the excitation source; SS is the difference in wavelength or frequency units between the maxima of the first photoabsorption band and the fluorescence band. On the other hand, the Förster resonance energy transfer (FRET)-based sensor is useful for applications in biochemistry and environmental research such as nucleic acid and ion analysis, signal transduction, and light harvesting, as well as for designing ratiometric fluorescent sensors. ${ }^{11,12}$ FRET is well described as an energy transfer process between an excited-state donor fluorophore and a ground-state acceptor fluorophore linked together by a non-conjugated spacer, and, as a result, a fluorescence spectrum from the acceptor fluorophore is observed. In order to achieve an effective FRET, a strong spectral overlap between the donor fluorescence and the acceptor photoabsorption is required. Consequently, the pseudoSS between the maxima of the donor photoabsorption band and acceptor fluorescence band of the FRET-based sensor is larger than the SS of either the donor or acceptor fluorophore, leading to an effective avoidance of self-quenching and fluorescence detection errors. Thus, in our previous work, in order to develop a fluorescent sensor possessing a large SS for the detection of water in solvents, we have designed and synthesized a PET/FRETbased fluorescent sensor DJ-1 composed of anthracene-(aminomethyl)phenylboronic acid ester as the donor fluorophore with PET characteristics and a BODIPY skeleton as the acceptor fluorophore in the FRET process (Fig. 1c). ${ }^{13}$ In fact, the enhancement of the fluorescence band originating from the BODIPY skeleton was observed upon addition of water to an acetonitrile solution of DJ-1 due to both the suppression of PET in the donor fluorophore (anthracene-(aminomethyl)phenylboronic acid ester) and the occurrence of FRET from the excited-state donor fluorophore to the ground-state acceptor fluorophore (BODIPY skeleton) (Fig. 2a). It was found that the PET/FRET-based fluorescent dye composed of the PET-type donor fluorophore and the acceptor fluorophore in the FRET process can act as a fluorescent sensor with a large SS for the detection of a trace amount of water in solvents. Thus, it is expected that the development of a PET/FRET-based fluorescent sensor will allow the creation of a fluorescent sensor system with a large SS for the detection of water in solvents, that is, the PET/FRET-based fluorescent 


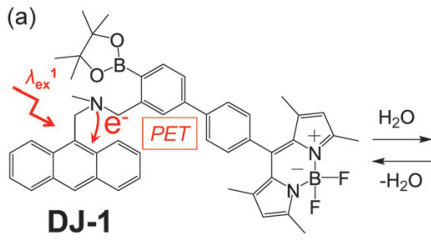

Non fluorescence (PET active and FRET inactive)

(b)

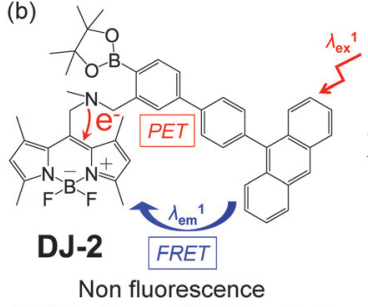

(PET active and FRET active)

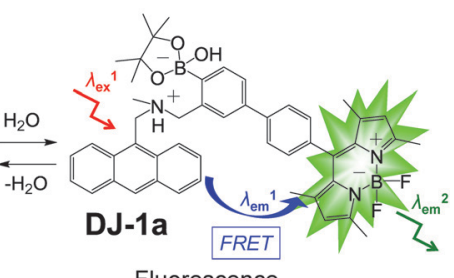

Fluorescence

(PET inactive and FRET active)

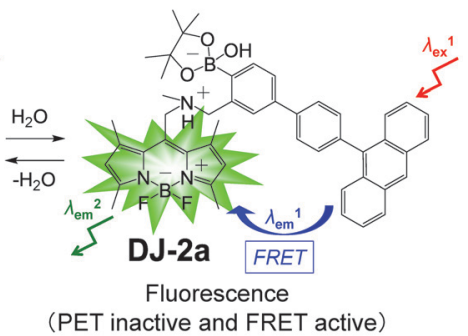

Fig. 2 Proposed mechanisms of PET/FRET-type fluorescent sensors (a) DJ-1 and (b) DJ-2 for the detection of water in a solvent.

sensor has the advantage over a PET-based fluorescent sensor ${ }^{4,5}$ with a very small SS.

In this work, in order to provide a direction in molecular design toward creating a highly efficient PET/FRET-based fluorescent sensor for water content determination in organic solvents, we have newly designed and synthesized a PET/FRET-based fluorescent sensor DJ-2, where the anthracene skeleton and BODIPY-(aminomethyl)phenylboronic acid ester skeleton are the donor fluorophore and the PET-type acceptor fluorophore in the FRET process, respectively (Fig. 1c). It is expected that for $\mathbf{D J}-\mathbf{2}$ in absolute solvents, FRET takes place from the excited-state donor fluorophore (anthracene skeleton) to the ground-state acceptor fluorophore (BODIPY skeleton), but fluorescence emission originating from the acceptor fluorophore is not observed due to the occurrence of PET in the BODIPY-(aminomethyl)phenylboronic acid ester skeleton (Fig. 2b). On the other hand, as with the case of DJ-1, the addition of water to organic solvents containing DJ-2 causes both PET suppression and energy transfer from the anthracene to the BODIPY skeleton through the FRET process, thus resulting in the enhancement of the fluorescence band originating from the BODIPY skeleton. Based on the obtained results and the fluorescence sensing mechanism of $\mathbf{D J}-\mathbf{1}$ and $\mathbf{D J}-\mathbf{2}$ for water, we propose a molecular design to create an efficient PET/FRET-based fluorescent sensor for water content determination in organic solvents.

\section{Results and discussion}

The PET/FRET-based fluorescent sensors DJ-1 and DJ-2 were synthesized according to a stepwise synthetic protocol. The synthesis of DJ-1, which is composed of anthracene-(aminomethyl)phenylboronic acid ester as the PET-type donor fluorophore and BODIPY skeleton as the acceptor fluorophore in the FRET process, as well as the PET-based fluorescent sensor OM-1 and B-1 as a reference to DJ-1 (Fig. 1d), has been reported elsewhere. ${ }^{13}$ The synthetic pathway of $\mathbf{D J - 2}$, which is composed of an anthracene skeleton as the donor fluorophore and

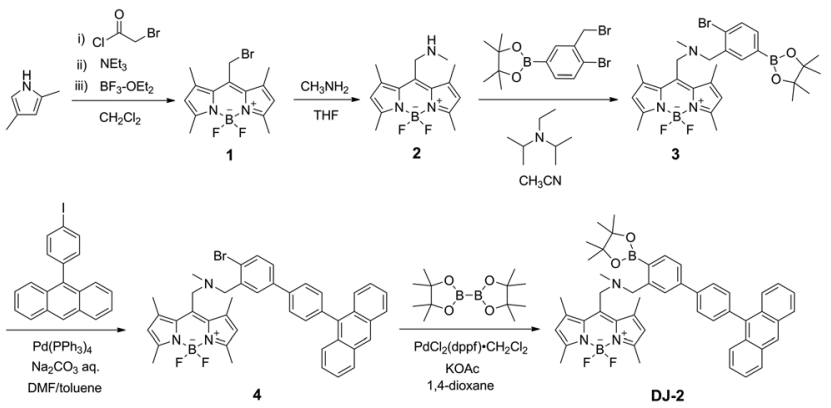

Scheme 1 Synthesis of DJ-2.

BODIPY-(aminomethyl)phenylboronic acid ester skeleton as the PET-type acceptor fluorophore in the FRET process, is shown in Scheme 1. We first prepared BODIPY 1 by the reaction of 2,4-dimethylpyrrole with bromoacetyl chloride followed by treatment with $\mathrm{BF}_{3} \cdot \mathrm{OEt}_{2}$. The BODIPY 1 was reacted with methyl amine to give BODIPY 2. The reaction of 2 with 2-(4-bromo-3(bromomethyl)phenyl)-4,4,5,5-tetramethyl-1,3,2-dioxaborolane in the presence of $N, N$-diisopropylethylamine yielded compound 3 . A PET/FRET-based derivative $\mathbf{4}$ was prepared by Suzuki coupling of 9-(4-iodophenyl)anthracene (see Scheme S1 for the synthesis, ESI $\dagger$ ) with the compound 3. Finally, we obtained DJ-2 from compound 4 with bis(pinacolato)diboron via the Miyaura borylation reaction. As a reference for $\mathbf{D J}-\mathbf{2}$, the anthracene derivative $\mathbf{A}-\mathbf{1}$ was prepared by Suzuki coupling of 9-(4-iodophenyl)anthracene with phenylboronic acid (Fig. 1d, see Scheme S2 for the synthesis, ESI $\dagger$ ). Also, we prepared a PET-based fluorescent sensor MH-2 by the reaction of 2 with 2-(2-(bromomethyl)phenyl)-4,4,5,5-tetramethyl1,3,2-dioxaborolane (Fig. 1d, see Scheme S3 for the synthesis, ESI $\dagger$ ).

The photoabsorption and fluorescence spectra of OM-1, MH-2, A-1, B-1, DJ-1 and DJ-2 in acetonitrile are shown in Fig. 3. OM-1 and B-1, which are structural components for DJ-1, show photoabsorption bands in the ranges of $300 \mathrm{~nm}$ to $400 \mathrm{~nm}$ and $420 \mathrm{~nm}$ to $520 \mathrm{~nm}$ originating from the anthracene skeleton and the BODIPY skeleton, respectively (Fig. 3a). In addition, for B-1, a feeble and broad photoabsorption band was observed in the range of $300 \mathrm{~nm}$ to $400 \mathrm{~nm}$. The molar extinction coefficient $\left(\varepsilon_{\max }\right)$ for the photoabsorption maximum $\left(\lambda_{\max }^{\mathrm{abs}}=498 \mathrm{~nm}\right)$ of $\mathbf{B}-\mathbf{1}$ is $72600 \mathrm{M}^{-1} \mathrm{~cm}^{-1}$, which is significantly higher than that $\left(\lambda_{\max }^{\mathrm{abs}}=366 \mathrm{~nm}, \varepsilon_{\max }=6800 \mathrm{M}^{-1} \mathrm{~cm}^{-1}\right)$ of OM-1. On the other hand, DJ-1 shows two photoabsorption bands in the ranges of $300 \mathrm{~nm}$ to $400 \mathrm{~nm}\left(\lambda_{\max }^{\mathrm{abs}}=367 \mathrm{~nm}, \varepsilon_{\max }=14200 \mathrm{M}^{-1} \mathrm{~cm}^{-1}\right)$ and $420 \mathrm{~nm}$ to $520 \mathrm{~nm}\left(\lambda_{\max }^{\mathrm{abs}}=498 \mathrm{~nm}, \varepsilon_{\max }=72200 \mathrm{M}^{-1} \mathrm{~cm}^{-1}\right)$, which are assigned to the anthracene skeleton and the BODIPY skeleton, respectively. $\mathbf{M H - 2}$ and $\mathbf{A - 1}$, which are structural components for DJ-2, show photoabsorption bands in the ranges of $430 \mathrm{~nm}$ to $540 \mathrm{~nm}$ and $300 \mathrm{~nm}$ to $400 \mathrm{~nm}$ originating from the BODIPY skeleton and the anthracene skeleton, respectively (Fig. 3c). As with the case of B1, for $\mathbf{M H}-2$, a feeble and broad photoabsorption band was observed in the range of $300 \mathrm{~nm}$ to $400 \mathrm{~nm}$. The $\varepsilon_{\max }$ value for $\lambda_{\max }^{\text {abs }}$ at $510 \mathrm{~nm}$ of MH-2 is $82900 \mathrm{M}^{-1} \mathrm{~cm}^{-1}$, which is significantly higher than that $\left(\lambda_{\max }^{\mathrm{abs}}=367 \mathrm{~nm}, \varepsilon_{\max }=11100 \mathrm{M}^{-1} \mathrm{~cm}^{-1}\right)$ of A-1. In addition, as with the case of DJ-1, DJ-2 shows two photoabsorption bands in 

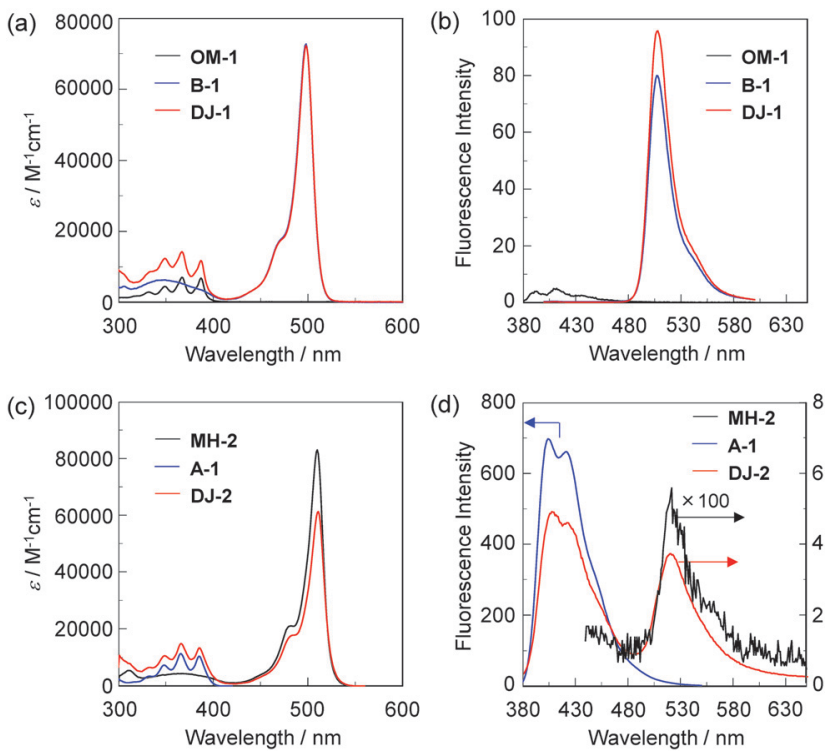

Fig. 3 (a) Photoabsorption and (b) fluorescence ( $\lambda^{\text {ex }}=366 \mathrm{~nm}$ for OM-1 and $367 \mathrm{~nm}$ for B-1 and DJ-1) spectra of OM-1 $\left(c=2.0 \times 10^{-5} \mathrm{M}\right)$, B-1 (c $\left.=4.0 \times 10^{-6} \mathrm{M}\right)$, and DJ-1 $\left(c=4.0 \times 10^{-6} \mathrm{M}\right)$ in acetonitrile. (c) Photoabsorption and (d) fluorescence ( $\lambda^{\mathrm{ex}}=367 \mathrm{~nm}$ for $\mathbf{M H}-2$ and DJ-2, and $366 \mathrm{~nm}$ for A-1) spectra of MH-2 (c = 4.0 $\left.\times 10^{-6} \mathrm{M}\right), \mathbf{A - 1}(\mathrm{c}=$ $\left.2.0 \times 10^{-5} \mathrm{M}\right)$, and $\mathbf{D J}-2\left(c=4.0 \times 10^{-6} \mathrm{M}\right)$ in acetonitrile.

the ranges of $300 \mathrm{~nm}$ to $400 \mathrm{~nm}\left(\lambda_{\max }^{\mathrm{abs}}=367 \mathrm{~nm}, \varepsilon_{\max }=\right.$ $\left.14800 \mathrm{M}^{-1} \mathrm{~cm}^{-1}\right)$ and $430 \mathrm{~nm}$ to $540 \mathrm{~nm}\left(\lambda_{\max }^{\mathrm{abs}}=511 \mathrm{~nm}, \varepsilon_{\max }=\right.$ $61300 \mathrm{M}^{-1} \mathrm{~cm}^{-1}$ ) originating from the anthracene skeleton and the BODIPY skeleton, respectively. In the corresponding fluorescence spectra, OM-1 and B-1 exhibit a fluorescence maximum $\left(\lambda_{\max }^{\mathrm{fl}}\right)$ at $412 \mathrm{~nm}$ and $507 \mathrm{~nm}$ upon photoexcitation $\left(\lambda^{\mathrm{ex}}\right)$ at $366 \mathrm{~nm}$ and $367 \mathrm{~nm}$, respectively (Fig. 3b). It is worth mentioning here that the edge for the fluorescence band of OM-1 reached $500 \mathrm{~nm}$, that is, the photoabsorption spectrum originating from the BODIPY skeleton of B-1 has a spectral overlap with the fluorescence spectrum originating from the anthracene skeleton of OM-1. This result suggests that for DJ-1, the FRET from the anthracene skeleton as the donor fluorophore to the BODIPY skeleton as the acceptor fluorophore occurs upon photoexcitation of the anthracene skeleton. In fact, DJ-1 exhibits only one fluorescence band with the $\lambda_{\max }^{\mathrm{fl}}$ at $508 \mathrm{~nm}$ in the range of $480 \mathrm{~nm}$ to $600 \mathrm{~nm}$ originating from the BODIPY skeleton upon photoexcitation $\left(\lambda^{\mathrm{ex}}=367 \mathrm{~nm}\right)$ of the anthracene skeleton, as well as photoexcitation ( $\lambda^{\mathrm{ex}}=472 \mathrm{~nm}$ ) of the BODIPY skeleton (Fig. S10, ESI $\dagger$ ). On the other hand, upon photoexcitation $\left(\lambda^{\mathrm{ex}}\right)$ at $367 \mathrm{~nm}, \mathbf{M H}-2$ exhibits a feeble fluorescence band with the $\lambda_{\max }^{\mathrm{fl}}$ at $520 \mathrm{~nm}$, whereas A-1 exhibits an intense fluorescence band (fluorescence quantum yield $\left(\Phi_{\mathrm{fl}}\right)=57 \%$ ) with the $\lambda_{\max }^{\mathrm{fl}}$ at $404 \mathrm{~nm}$, and the edge of the fluorescence band reached $530 \mathrm{~nm}$ (Fig. 3d). Therefore, the photoabsorption spectrum originating from the BODIPY skeleton of $\mathbf{M H}-2$ has a spectral overlap with the fluorescence spectrum originating from the anthracene skeleton of A-1, indicating the occurrence of FRET in DJ-2 from the anthracene skeleton to the BODIPY skeleton upon photoexcitation of the anthracene skeleton. However, in contrast to the case of DJ-1, DJ-2 exhibits two fluorescence bands with the $\lambda_{\max }^{\mathrm{fl}}$ at $407 \mathrm{~nm}$ and the $\lambda_{\max }^{\mathrm{fl}}$ at $520 \mathrm{~nm}$ originating from the anthracene skeleton and the BODIPY skeleton, respectively, upon photoexcitation ( $\lambda^{\mathrm{ex}}=367 \mathrm{~nm}$ ) of the anthracene skeleton, although DJ-2 shows only one fluorescence band with the $\lambda_{\text {max }}^{\text {fl }}$ at $520 \mathrm{~nm}$ originating from the BODIPY skeleton upon photoexcitation $\left(\lambda^{\mathrm{ex}}=486 \mathrm{~nm}\right)$ of the BODIPY skeleton (Fig. S12, ESI $\dagger$ ). Thus, we considered the differences in the fluorescence properties between DJ-1 and DJ-2 based on the FRET efficiency. Obviously, in absolute acetonitrile, the FRET efficiency for DJ-1 is quantitative due to the fact that no fluorescence band originating from the anthracene skeleton is observed. In contrast, the FRET efficiency for $\mathrm{DJ}-2$ is estimated to be $53 \%$ from the equation $E_{\mathrm{FRET}}=$ $1-\left(\tau_{\mathrm{DA}} / \tau_{\mathrm{D}}\right)$ based on time-resolved fluorescence lifetime measurements, where $\tau_{\mathrm{DA}}$ and $\tau_{\mathrm{D}}$ are the donor fluorescence lifetimes in the presence and absence of an acceptor, that is, $\tau_{\mathrm{DA}}$ and $\tau_{\mathrm{D}}$ are the fluorescence lifetimes of DJ-2 (2.0 ns) and A-1 (4.2 ns), respectively. Indeed, this result indicates that the FRET efficiency for DJ-1 is higher than that for DJ-2. The reason for the inferior $E_{\text {FRET }}$ value of DJ-2 might be not only the intense fluorescence emission originating from the anthracene skeleton (actually, the $\Phi_{\mathrm{fl}}$ value of A-1 is 57\%) that is too strong for the BODIPY skeleton to absorb sufficiently, but also the poor overlap integral of the donor fluorescence spectrum with the acceptor photoabsorption spectrum, compared to the overlap integral in $\mathbf{D J - 1}$, although DJ-1 and DJ-2 have the same spatial distance between the donor and the acceptor fluorophores. Nevertheless, based on the photoabsorption and fluorescence properties of OM-1, MH-2, A-1, B-1, DJ-1 and DJ-2, it is expected that the addition of water to organic solvents containing DJ-1 or DJ-2 causes both PET suppression in the anthracene- or BODIPY-(aminomethyl)phenylboronic acid ester and energy transfer from anthracene skeleton to BODIPY skeleton through the FRET process, thus resulting in the enhancement of the fluorescence band originating from the BODIPY skeleton. In addition, it was found that the pseudo-SS value of DJ-1 and DJ-2 between the $\lambda_{\max }^{\mathrm{abs}}$ of the anthracene skeleton and the $\lambda_{\max }^{\mathrm{fl}}$ of the BODIPY skeleton is $7563 \mathrm{~cm}^{-1}(141 \mathrm{~nm})$ and $8017 \mathrm{~cm}^{-1}(153 \mathrm{~nm})$, respectively, which are significantly higher than those of OM-1 $\left(395 \mathrm{~cm}^{-1}\right)$ and B-1 $\left(356 \mathrm{~cm}^{-1}\right)$, and those of MH-2 $\left(377 \mathrm{~cm}^{-1}\right)$ and A-1 $\left(1222 \mathrm{~cm}^{-1}\right)$, respectively.

In order to investigate the optical sensing ability of DJ-1 for water in acetonitrile, the photoabsorption and fluorescence spectra of OM-1 and B-1 were measured in acetonitrile that contained various concentrations of water, as a reference to DJ-1 (Fig. 4). The photoabsorption spectra of OM-1 did not undergo appreciable changes upon the addition of water to the acetonitrile solution (Fig. 4a), but the fluorescence spectra of OM-1 underwent an increase in fluorescence intensity at around $415 \mathrm{~nm}$ with the increase in the water content, which is attributed to the fluorescence emission originating from the anthracene skeleton due to the suppression of PET (Fig. 4b). On the other hand, the photoabsorption and fluorescence spectra of B-1 did not undergo appreciable changes upon the addition of water to the acetonitrile solution (Fig. 4c, d and Fig. S11, ESI $\dagger$ ). As with the case of OM-1, the photoabsorption spectra of DJ-1 show unnoticeable changes upon the addition of water to the acetonitrile solution (Fig. 4e). However, for the corresponding fluorescence spectra, it is worth mentioning here that 

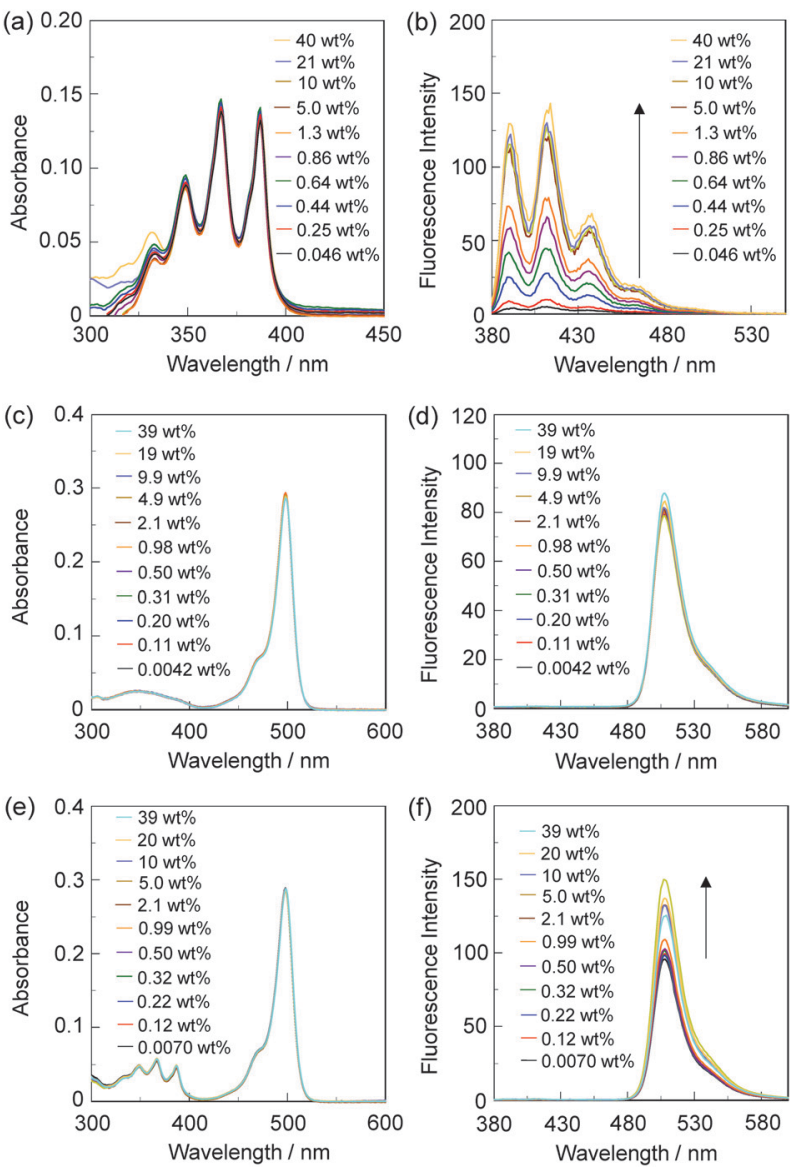

Fig. 4 (a) Photoabsorption and (b) fluorescence spectra $\left(\lambda^{\mathrm{ex}}=366 \mathrm{~nm}\right)$ of OM-1 $\left(c=2.0 \times 10^{-5} \mathrm{M}\right)$ in acetonitrile containing water $(0.046-40 \mathrm{wt} \%)$ (c) Photoabsorption and (d) fluorescence spectra $\left(\lambda^{\mathrm{ex}}=367 \mathrm{~nm}\right)$ of B-1 ( $\left.c=4.0 \times 10^{-6} \mathrm{M}\right)$ in acetonitrile containing water $(0.0042-39 \mathrm{wt} \%)$. (e) Photoabsorption and (f) fluorescence spectra $\left(\lambda^{\mathrm{ex}}=367 \mathrm{~nm}\right)$ of DJ-1 $\left(c=4.0 \times 10^{-6} \mathrm{M}\right)$ in acetonitrile containing water $(0.0070-39 \mathrm{wt} \%)$.

DJ-1 exhibits an enhancement of fluorescence band at $508 \mathrm{~nm}$ originating from the BODIPY skeleton due to the photoexcitation $\left(\lambda^{\mathrm{ex}}=367 \mathrm{~nm}\right)$ of the anthracene skeleton upon the addition of water to the acetonitrile solution (Fig. 4f). The enhancement of the fluorescence band levels off when the water content becomes $5.0 \mathrm{wt} \%$ as with the case of OM-1. This result indicates that the enhancement of fluorescence band originating from the BODIPY skeleton is attributed to both the suppression of PET in the anthracene-(aminomethyl)phenylboronic acid ester and the occurrence of FRET from the excited-state anthracene fluorophore to the ground-state BODIPY fluorophore upon addition of water to the acetonitrile solution. Moreover, the fluorescence spectra of DJ-1 by the photoexcitation $\left(\lambda^{\text {ex }}=\right.$ $472 \mathrm{~nm}$ ) of the BODIPY skeleton did not undergo appreciable changes in intensity and shape of the fluorescence band originating from the BODIPY skeleton upon addition of water to the acetonitrile solution, which is additional evidence for the FRET process in DJ-1, (Fig. S10, ESI $\dagger$ ). Consequently, as shown in Fig. 2a, these facts strongly propose that for DJ-1, the enhancement of the fluorescence band upon addition of water to the solution is due to both the suppression of PET and the occurrence of FRET in the PET/FRET-based fluorophore skeleton. As with the case of DJ-1, the optical sensing ability of DJ-2 for water as well as MH-2 and A-1 in acetonitrile that contained various concentrations of water was investigated by photoabsorption and fluorescence spectral measurements (Fig. 5). The photoabsorption spectra of MH-2 did not undergo appreciable changes upon addition of water to the acetonitrile solution (Fig. 5a). On the other hand, the fluorescence spectra of MH-2 upon photoexcitation $\left(\lambda^{e x}=367 \mathrm{~nm}\right)$ showed an increase in intensity with a red-shift $(c a .15 \mathrm{~nm})$ of the fluorescence peak wavelength at $520 \mathrm{~nm}$ in the water content region greater than $5.0 \mathrm{wt} \%$, which is attributed to the fluorescence emission originating from the BODIPY skeleton due to the suppression of PET (Fig. 5b). A similar result was also obtained in the fluorescence spectra of MH-2 upon photoexcitation $\left(\lambda^{\text {ex }}=485 \mathrm{~nm}\right)$ of the BODIPY skeleton (Fig. S12, ESI $\dagger$ ). On the other hand, the photoabsorption and fluorescence spectra of A-1 did not undergo appreciable changes upon the addition of water to the acetonitrile solution (Fig. 5c, d, and Fig. S13, ESI †). As with the case of $\mathbf{M H - 2}$, the photoabsorption spectra of DJ-2 showed unnoticeable changes
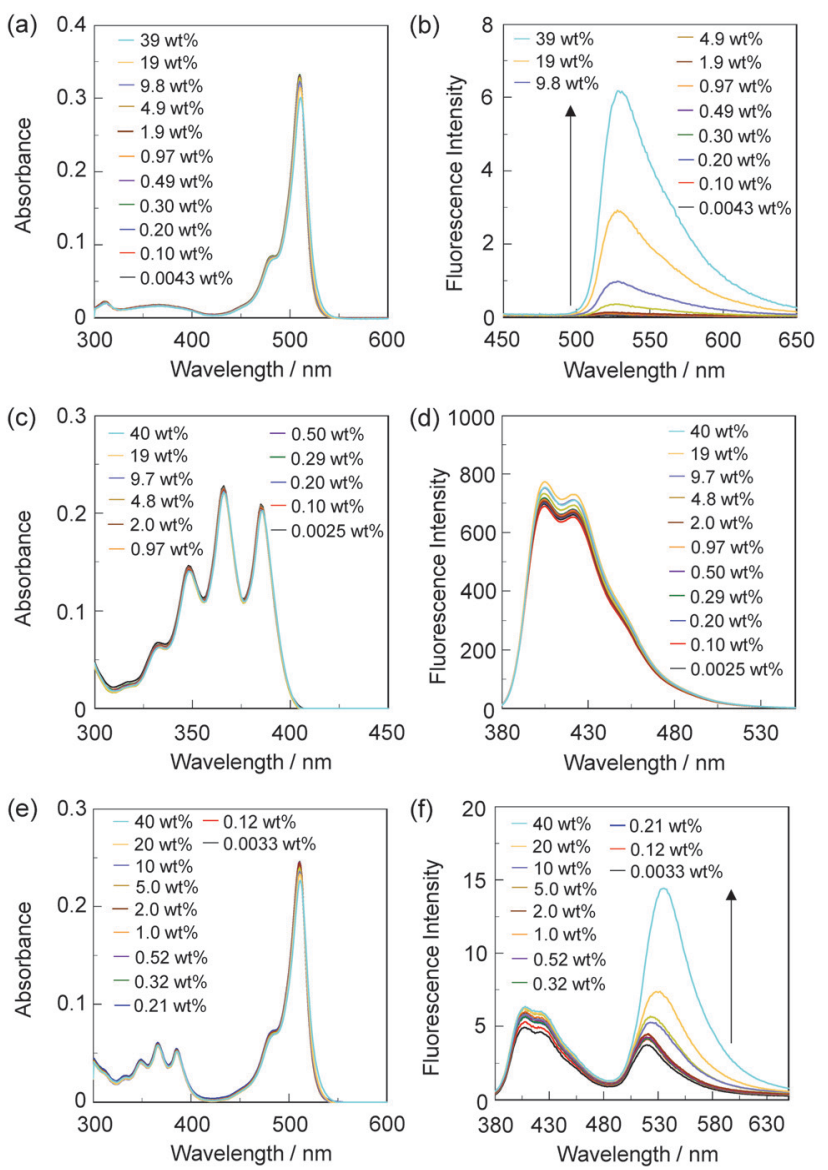

Fig. 5 (a) Photoabsorption and (b) fluorescence spectra $\left(\lambda^{\mathrm{ex}}=367 \mathrm{~nm}\right)$ of MH-2 $\left(c=4.0 \times 10^{-6} \mathrm{M}\right)$ in acetonitrile containing water $(0.0043-39 \mathrm{wt} \%)$. (c) Photoabsorption and (d) fluorescence spectra $\left(\lambda^{\text {ex }}=366 \mathrm{~nm}\right)$ of A-1 ( $c=2.0 \times 10^{-5} \mathrm{M}$ ) in acetonitrile containing water $(0.0025-40 \mathrm{wt} \%)$. (e) Photoabsorption and (f) fluorescence spectra $\left(\lambda^{\mathrm{ex}}=367 \mathrm{~nm}\right)$ of DJ-2 (c = $\left.4.0 \times 10^{-6} \mathrm{M}\right)$ in acetonitrile containing water $(0.0033-40 \mathrm{wt} \%)$. 
upon the addition of water to the acetonitrile solution (Fig. 5e). In addition, DJ-2 exhibits an enhancement and red-shift (ca. $15 \mathrm{~nm}$ ) of the fluorescence band at $520 \mathrm{~nm}$ originating from the BODIPY skeleton upon the photoexcitation $\left(\lambda^{\mathrm{ex}}=367 \mathrm{~nm}\right)$ of the anthracene skeleton in the water content region greater than $5.0 \mathrm{wt} \%$ (Fig. 5f), but the fluorescence band at around $410 \mathrm{~nm}$ originating from the anthracene skeleton does not undergo appreciable changes upon the addition of water to the acetonitrile solution, which might be attributed to the low FRET efficiency. This result indicates that the enhancement of fluorescence band originating from the BODIPY skeleton is attributed to both the PET suppression in the BODIPY-(aminomethyl)phenylboronic acid ester and the FRET process from the excited-state anthracene fluorophore to the ground-state BODIPY fluorophore upon addition of water to the acetonitrile solution. As additional evidence for the suppression of PET in DJ-2 upon the addition of water to the acetonitrile solution, the fluorescence spectra of DJ-2 upon photoexcitation ( $\lambda^{\mathrm{ex}}=486 \mathrm{~nm}$ ) of the BODIPY skeleton showed similar changes to the case of the photoexcitation $\left(\lambda^{\mathrm{ex}}=367 \mathrm{~nm}\right)$ of the anthracene skeleton (Fig. S14, ESI $\dagger$ ), as well as the case of MH-2. As shown in Fig. 2b, these facts strongly indicate that for DJ-2 in absolute solvent, FRET takes place from the excited-state donor fluorophore (anthracene skeleton) to the ground-state acceptor fluorophore (BODIPY skeleton), although the fluorescence emission originating from the acceptor fluorophore is not observed due to the PET in the BODIPY-(aminomethyl)phenylboronic acid ester skeleton. On the other hand, the addition of water to the acetonitrile solution containing DJ-2 causes both PET suppression and energy transfer from anthracene to BODIPY skeleton through the FRET process, thus resulting in the enhancement of the fluorescence band originating from the BODIPY skeleton. For both DJ-1 and DJ-2, similar results were obtained in the case of THF.

On the basis of the above results, we considered the optical sensing ability of DJ-1 and DJ-2 for water in a solvent. Evidently, as with the case of DJ-1 in absolute acetonitrile, the FRET efficiency of DJ-1 in acetonitrile solution containing water is quantitative due to the fact that no fluorescence band originating from the anthracene skeleton is observed. On the other hand, based on the equation $E_{\mathrm{FRET}}=1-\left(\tau_{\mathrm{DA}} / \tau_{\mathrm{D}}\right)$ and the time-resolved fluorescence lifetime measurements, the FRET efficiency of DJ-2 in an acetonitrile solution containing a water content of $40 \mathrm{wt} \%$ is estimated to be $49 \%$, which is a similar value to the case of absolute acetonitrile solution $\left(E_{\mathrm{FRET}}=53 \%\right)$. Therefore, this fact doubtlessly indicates that DJ-1 is composed of a PET-type donor fluorophore and an acceptor fluorophore in the FRET process that can act as an efficient PET/FRET-based fluorescent sensor for water, compared with DJ-2 composed of a donor fluorophore and a PET-type acceptor fluorophore in the FRET process.

In order to estimate the sensitivity and accuracy of DJ-1 and DJ-2 as a PET/FRET-based fluorescent sensor for the detection of water in solvent, the changes in fluorescence intensity were plotted against the water fraction in acetonitrile (Fig. 6 and 7). As with the case of OM-1 (Fig. 6a), the plot of DJ-1 in the low water content region below $1.0 \mathrm{wt} \%$ demonstrated that the fluorescence peak intensity at $508 \mathrm{~nm}$ increased linearly as a
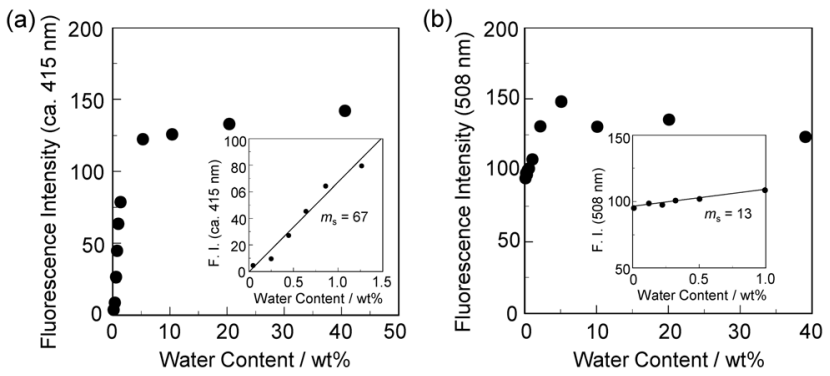

Fig. 6 Fluorescence peak intensity at (a) around $415 \mathrm{~nm}$ of OM-1 ( $\lambda^{\mathrm{ex}}=$ $366 \mathrm{~nm}$ ) and (b) $508 \mathrm{~nm}$ of DJ-1 ( $\lambda^{\mathrm{ex}}=367 \mathrm{~nm}$ ) as a function of water content below $40 \mathrm{wt} \%$ in acetonitrile. Inset in (a): Fluorescence peak intensity at around $415 \mathrm{~nm}$ of OM-1 ( $\lambda^{\mathrm{ex}}=366 \mathrm{~nm}$ ) as a function of water content below 1.3 wt\% in acetonitrile. Inset in (b): Fluorescence peak intensity at $508 \mathrm{~nm}$ of DJ-1 ( $\left.\lambda^{\mathrm{ex}}=367 \mathrm{~nm}\right)$ as a function of water content below $1.0 \mathrm{wt} \%$ in acetonitrile. (a)

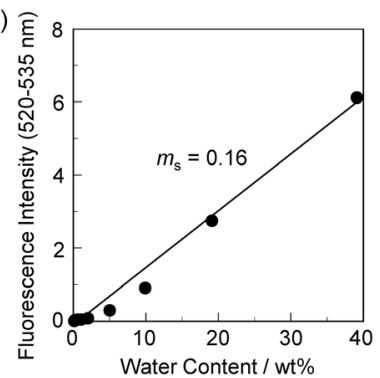

(b)

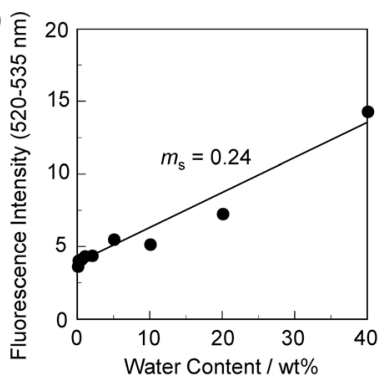

Fig. 7 Fluorescence peak intensity at $520-535 \mathrm{~nm}$ of (a) $\mathbf{M H - 2}\left(\lambda^{\mathrm{ex}}=\right.$ $367 \mathrm{~nm})$ and (b) DJ-2 ( $\lambda^{\mathrm{ex}}=367 \mathrm{~nm}$ ) as a function of water content below 40 wt\% in acetonitrile.

function of the water content (Fig. 6b inset). Indeed, the correlation coefficient $\left(R^{2}\right)$ value for the calibration curve is 0.96 , which indicates good linearity. The enhancement of the fluorescence peak intensity levels off in the water content region greater than $5.0 \mathrm{wt} \%$. However, the plots of $\mathbf{M H - 2}$ and DJ-2 in the low water content region below $1.0 \mathrm{wt} \%$ did not show good linearity for the changes in fluorescence peak intensity at 520-535 $\mathrm{nm}$ as a function of the water content. On the other hand, the plots of MH-2 and DJ-2 in the water content region below $40 \mathrm{wt} \%$ showed good linearity with the $R^{2}$ values of 0.99 for $\mathbf{M H}-2$ and 0.96 for $\mathbf{D J}-2$, that is, the fluorescence peak intensity at 520-535 $\mathrm{nm}$ increased linearly as a function of the water content (Fig. 7). In addition, we performed the measurement of $\Phi_{\mathrm{fl}}$ for $\mathbf{D J - 1}$ in the acetonitrile solution with various water contents. Indeed, these $\Phi_{\mathrm{fl}}$ values are in good agreement with the intensity of the fluorescence spectra (Fig. 8). Such a relationship between the $\Phi_{\mathrm{fl}}$ value and the fluorescence intensity was also observed in the case of DJ-2, although the $\Phi_{\mathrm{fl}}$ value was estimated from the fluorescence bands originating from both the anthracene skeleton and the BODIPY skeleton. (Fig. S15, ESI $\dagger$ ). These facts also indicate that the fluorescence sensing mechanism of the PET/FRET-based fluorescent sensors for water is based on the suppression of PET and occurrence of FRET by water molecules for DJ-1 and the suppression of PET and the utilization of FRET by water 

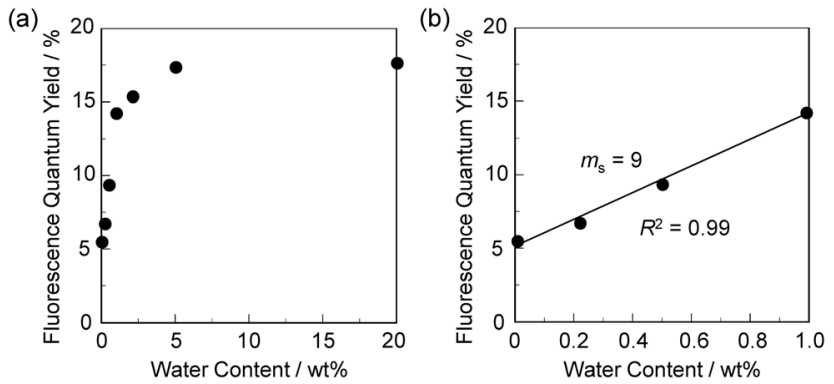

Fig. 8 Fluorescence quantum yield of DJ-1 upon photoexcitation at $367 \mathrm{~nm}$ as a function of water content (a) below $20 \mathrm{wt} \%$ and (b) at $1.0 \mathrm{wt} \%$ in acetonitrile.

molecules for DJ-2, respectively (Fig. 2). Thus, the detection limit (DL) of DJ-1 was determined from the plot of the fluorescence intensity at $508 \mathrm{~nm}$ versus the water fraction in the low water content region below $1.0 \mathrm{wt} \%\left(\mathrm{DL}=3.3 \sigma / \mathrm{m}_{\mathrm{s}}\right.$, where $\sigma$ is the standard deviation of the blank sample and $m_{\mathrm{s}}$ is the slope of the calibration curve). The $m_{\mathrm{s}}$ and DL values of DJ-1 are 13 and $0.25 \mathrm{wt} \%$, which are inferior to those of the PET-based fluorescent sensor OM-1 $\left(m_{\mathrm{s}}=67, \mathrm{DL}=0.04 \mathrm{wt} \%\right)$ (Fig. 6). ${ }^{6 a}$ The $m_{\mathrm{s}}$ and DL values of the PET/FRET-based fluorescent sensor may depend on the non-conjugated spacer between the donor fluorophore and the acceptor fluorophore, that is, the substituent on the phenylboronic acid pinacol ester. In fact, the $m_{\mathrm{s}}$ value (55) and DL value (0.06 wt\%) of OF-1 having a methoxy group as an electron-donating substituent are inferior to those of OM-1, but the $m_{\mathrm{s}}$ value (382) and DL value (0.009 wt\%) of OF-2 having a cyano group as an electron-withdrawing substituent are superior to those of OM-1 and OF-1. ${ }^{6 d}$ On the other hand, the DL values of $\mathbf{M H - 2}\left(m_{\mathrm{s}}=0.16\right)$ and DJ-2 $\left(m_{\mathrm{s}}=0.24\right)$ determined from the plots of the fluorescence intensity at $520-535 \mathrm{~nm}$ versus the water fraction below $40 \mathrm{wt} \%$ are over $10 \mathrm{wt} \%$ (Fig. 7), which are much inferior to those of OM-1 and DJ-1. The inferior DL values of MH-2 and DJ-2 might be attributed to the highly active PET characteristics of the BODIPY(aminomethyl)phenylboronic acid ester skeleton, compared to the anthracene-(aminomethyl)phenylboronic acid ester skeleton in OM-1 and DJ-1. These results suggest that the $m_{\mathrm{s}}$ and DL values of a PET/FRET-based fluorescent sensor for the detection of water can be improved not only by modifying the non-conjugated spacer between the donor fluorophore and the acceptor fluorophore, but also by selecting a PET-type fluorophore. Consequently, this work reveals that DJ-1 composed of a PET-type donor fluorophore and an acceptor fluorophore in the FRET process can act as an efficient PET/FRET-based fluorescent sensor for water, compared with DJ-2 composed of a donor fluorophore and a PET-type acceptor fluorophore in the FRET process.

\section{Conclusions}

We have designed and developed two different-types of PET/ FRET-based fluorescent sensors (DJ-1 and DJ-2) possessing a large SS for visualization, detection and quantification of water in solvents. DJ-1 is composed of a PET-type donor fluorophore (anthracene-(aminomethyl)phenylboronic acid ester) and an acceptor fluorophore (BODIPY skeleton) in the FRET process, but DJ-2 is composed of a donor fluorophore (anthracene skeleton) and a PET-type acceptor fluorophore (BODIPY-(aminomethyl)phenylboronic acid ester) in the FRET process. This work demonstrated that the FRET efficiency of DJ-1 is quantitative, but that of DJ-2 was estimated to be $c a$. $50 \%$ based on time-resolved fluorescence lifetime measurements. Moreover, it was found that the detection limit of $\mathbf{D J}-\mathbf{1}$ for water is superior to that of $\mathbf{D J} \mathbf{- 2}$. Based on the fluorescence sensing mechanisms of DJ-1 and DJ-2 for water, we propose that a combination of a PET-type donor fluorophore and an acceptor fluorophore in the FRET process is one of the most promising molecular designs to create an efficient fluorescent sensor for the detection of water in organic solvents.

\section{Experimental}

General

Melting points were measured using a Yanaco micro melting point apparatus MP model. IR spectra were recorded using a PerkinElmer Spectrum One FT-IR spectrometer using the ATR method. ${ }^{1} \mathrm{H}$ and ${ }^{13} \mathrm{C}$ NMR spectra were recorded using a Varian$500(500 \mathrm{MHz})$ FT NMR spectrometer. High-resolution mass spectral data by ESI and GC-FI were acquired using a Thermo Fisher Scientific LTQ Orbitrap XL and JEOL JMS-T100 GCV 4G, respectively. Photoabsorption spectra were recorded using a SHIMADZU UV-3150 spectrophotometer. Fluorescence spectra were measured using a Hitachi F-4500 spectrophotometer. The fluorescence quantum yields were determined using a HORIBA FluoroMax-4 spectrofluorometer with a calibrated integrating sphere system. Fluorescence decay measurements were performed using a HORIBA DeltaFlex modular fluorescence lifetime system, using a Nano LED pulsed diode excitation source $(370 \mathrm{~nm})$. The addition of water to the acetonitrile solutions containing OM-1, B-1, A-1, MH-2, DJ-1 and DJ-2 was made by weight percent (wt\%) until $40 \mathrm{wt} \%$ because the sensors $\mathbf{D J}-\mathbf{1}$ and $\mathbf{D J}-\mathbf{2}$ precipitated in the water content region greater than $40 \mathrm{wt} \%$. The determination of water content in acetonitrile was done with a MKC-610 and MKA-610 Karl Fischer moisture titrator (Kyoto Electronics manufacturing Co., Ltd) based on Karl Fischer coulometric titration for below $1.0 \mathrm{wt} \%$ and volumetric titration for $1.0-40 \mathrm{wt} \%$, respectively.

\section{Synthesis}

10-(Bromomethyl)-5,5-difluoro-1,3,7,9-tetramethyl-5H-4l4,5l4dipyrrolo[1,2-c:2', $\left.\mathbf{1}^{\prime}-f\right][1,3,2]$ diazaborinine (1). A solution of $2,4-$ dimethylpyrrole $(2.0 \mathrm{~mL}, 19 \mathrm{mmol})$ and bromoacetyl chloride $(0.84 \mathrm{~mL}, 10 \mathrm{mmol})$ in dichloromethane $(100 \mathrm{~mL})$ was refluxed for $1.5 \mathrm{~h}$ under a nitrogen atmosphere. Triethylamine $(7.0 \mathrm{~mL}$, $50.0 \mathrm{mmol}$ ) was added to the reaction mixture under a nitrogen atmosphere and stirred for $10 \mathrm{~min}$ at room temperature. Next, $\mathrm{BF}_{3} \cdot \mathrm{OEt}_{2}(26 \mathrm{~mL}, 100 \mathrm{mmol})$ was added dropwise and the solution was refluxed for $22 \mathrm{~h}$. The reaction mixture was washed with water and extracted with dichloromethane. The organic extract was dried over anhydrous $\mathrm{MgSO}_{4}$, filtrated, and concentrated. The residue 
was chromatographed on silica gel (dichloromethane: hexane = $1: 2$ as eluent) to give 1 ( $0.46 \mathrm{~g}, 14 \%$ yield) as a red solid; FT-IR (ATR): $\tilde{v}=2960,1556,1504,1195,1159,1066,1022,989 \mathrm{~cm}^{-1}$; ${ }^{1} \mathrm{H}$ NMR (500 MHz, $\left.\mathrm{CDCl}_{3}\right): \delta=2.54(\mathrm{~s}, 12 \mathrm{H}), 4.79(\mathrm{~s}, 2 \mathrm{H}), 6.10$ (s, 2H) ppm; ${ }^{13} \mathrm{C}$ NMR $\left(125 \mathrm{MHz}, \mathrm{CDCl}_{3}\right) \delta=14.84,15.68,37.30$, 122.42, 131.50, 136.07, 141.26, 156.79 ppm; HRMS (ESI): $m / z(\%):\left[\mathrm{M}+\mathrm{Na}^{+}\right]$calcd for $\mathrm{C}_{14} \mathrm{H}_{16} \mathrm{~N}_{2} \mathrm{BBrF}_{2} \mathrm{Na}$, 363.04502; found 363.04507 .

1-(5,5-Difluoro-1,3,7,9-tetramethyl-5H-4l4,5l4-dipyrrolo[1,2-c: $\left.2^{\prime}, \mathbf{1}^{\prime}-f\right][1,3,2]$ diazaborinin-10-yl)- $\mathrm{N}$-methylmethanamine (2). Methyl amine $(0.24 \mathrm{~mL}, 0.46 \mathrm{mmol})$ was added to a solution of $\mathbf{1}(0.077 \mathrm{~g}$, $0.23 \mathrm{mmol}$ ) in THF ( $4 \mathrm{~mL})$ and was refluxed for $1 \mathrm{~h}$. The reaction mixture was washed with water and extracted with dichloromethane. The organic extract was dried over anhydrous $\mathrm{MgSO}_{4}$, filtrated, and concentrated. The residue was chromatographed on silica gel (ethyl acetate : hexane $=1: 3$ as eluent) to give $2(0.048 \mathrm{~g}$, $72 \%$ yield) as an orange solid; m.p. $188-189{ }^{\circ} \mathrm{C}$; FT-IR (ATR): $\tilde{v}=$ 2951, 1548, 1506, 1193, 1157, 1058, 1024, $968 \mathrm{~cm}^{-1}$; ${ }^{1} \mathrm{H}$ NMR $\left(500 \mathrm{MHz} \mathrm{CDCl}_{3}\right): \delta=2.47(\mathrm{~s}, 6 \mathrm{H}), 2.51(\mathrm{~s}, 6 \mathrm{H}), 2.56(\mathrm{~s}, 3 \mathrm{H}), 3.89$ $(\mathrm{s}, 2 \mathrm{H}), 6.06(\mathrm{~s}, 2 \mathrm{H}) \mathrm{ppm} ;{ }^{13} \mathrm{C} \mathrm{NMR}\left(125 \mathrm{MHz} \mathrm{CDCl}_{3}\right): \delta=14.68$, 15.58, 36.80, 46.80, 121.89, 132.38, 140.40, 141.28, 155.22 ppm; HRMS (ESI): $m / z$ (\%): $[\mathrm{M}+\mathrm{H}]^{+}$calcd for $\mathrm{C}_{15} \mathrm{H}_{21} \mathrm{~N}_{3} \mathrm{BF}_{2}, 292.17911$; found 292.17905 .

$N$-(2-Bromo-5-(4,4,5,5-tetramethyl-1,3,2-dioxaborolan-2-yl)benzyl)1-(5,5-difluoro-1,3,7,9-tetramethyl-5H-4l4,5l4-dipyrrolo[1,2-c:2' $\mathbf{1}^{\prime}$ $f][1,3,2]$ diazaborinin-10-yl)- $N$-methylmethanamine (3). A solution of 2 (0.046 g, $0.16 \mathrm{mmol}), 2$-(4-bromo-3-(bromomethyl)phenyl)4,4,5,5-tetramethyl-1,3,2-dioxaborolane ( $0.059 \mathrm{~g}, 0.16 \mathrm{mmol}), N, N$ diisopropylethylamine $(0.11 \mathrm{~mL}, 0.64 \mathrm{mmol})$, and acetonitrile $(6 \mathrm{~mL})$ was refluxed for $3 \mathrm{~h}$ under a nitrogen atmosphere. After concentrating under reduced pressure, the resulting residue was dissolved in dichloromethane and washed with water. The dichloromethane extract was dried over anhydrous $\mathrm{MgSO}_{4}$, filtrated, and evaporated under reduced pressure. The residue was chromatographed on silica gel (ethyl acetate: hexane $=1: 3$ as eluent) to give 3 (0.064 g, 68\%yield) as an orange solid; m.p. 202-203 ${ }^{\circ}$ C; FT-IR (ATR): $\tilde{v}=2974,1546,1508,1344,1195,1159$, 1141, 1060, 1016, $964 \mathrm{~cm}^{-1} ;{ }^{1} \mathrm{H}$ NMR (500 MHz, $\left.\mathrm{CDCl}_{3}\right): \delta=1.33$ (s, 12H), 2.29 (s, 3H), $2.49(\mathrm{~s}, 6 \mathrm{H}), 2.52(\mathrm{~s}, 6 \mathrm{H}), 3.78(\mathrm{~s}, 2 \mathrm{H}), 3.93$ (s, 2H), $6.06(\mathrm{~s}, 2 \mathrm{H}), 7.49(\mathrm{~m}, 2 \mathrm{H}), 7.67(\mathrm{~s}, 1 \mathrm{H}) \mathrm{ppm} ;{ }^{13} \mathrm{C}$ NMR $\left(125 \mathrm{MHz}, \mathrm{CDCl}_{3}\right): \delta=14.73,17.52,25.02,41.63,51.83,59.78$, $84.10,122.28,128.81,132.51,133.47,134.95,136.71,138.02$, $140.45,142.42,154.96 \mathrm{ppm}$ (one aromatic carbon signal was not observed owing to overlapping resonances); HRMS (ESI): $\mathrm{m} / \mathrm{z}$ (\%): $[\mathrm{M}+\mathrm{H}]^{+}$calcd for $\mathrm{C}_{28} \mathrm{H}_{37} \mathrm{O}_{2} \mathrm{~N}_{3} \mathrm{~B}_{2} \mathrm{BrF}_{2}, 586.22178$; found 586.22198 .

1-(4'-(Anthracen-9-yl)-4-bromo-[1,1'-biphenyl]-3-yl)- $N$-((5,5-difluoro-1,3,7,9-tetramethyl-5H-4l4,5l4-dipyrrolo[1,2-c:2', $\left.1^{\prime}-f\right][1,3,2]-$ diazaborinin-10-yl)methyl)- $\mathrm{N}$-methylmethanamine (4). A solution of $3(0.30 \mathrm{~g}, 0.51 \mathrm{mmol}), 9-(4$-iodophenyl)anthracene $(0.25 \mathrm{~g}$, $0.67 \mathrm{mmol}$, see Scheme $\mathrm{S} 1$ for the synthesis, $\mathrm{ESI} \dagger), \mathrm{Pd}\left(\mathrm{PPh}_{3}\right)_{4}$ $(0.34 \mathrm{~g}, 0.30 \mathrm{mmol})$, and $2 \mathrm{M} \mathrm{Na}_{2} \mathrm{CO}_{3}$ aq. $(7.7 \mathrm{~mL}, 15 \mathrm{mmol})$ in a mixture solvent of DMF $(28 \mathrm{~mL})$ and toluene $(18 \mathrm{~mL})$ was stirred for $20 \mathrm{~min}$ at $90{ }^{\circ} \mathrm{C}$ under a nitrogen atmosphere. After concentrating under reduced pressure, the resulting residue was dissolved in dichloromethane and washed with water. The dichloromethane extract was dried over anhydrous $\mathrm{MgSO}_{4}$, filtrated, and evaporated under reduced pressure. The residue was chromatographed on silica gel (dichloromethane $:$ hexane $=2: 1$ as eluent) to give 4 (0.25 g, 68\% yield) as a red solid; m.p. 222-224 ${ }^{\circ} \mathrm{C}$; FT-IR (ATR): $\tilde{v}=2951,1544,1508,1305,1193,1157,1076,1022,974 \mathrm{~cm}^{-1}$; ${ }^{1} \mathrm{H}$ NMR $\left(500 \mathrm{MHz}, \mathrm{CDCl}_{3}\right): \delta=2.41(\mathrm{~s}, 3 \mathrm{H}), 2.51(\mathrm{~s}, 6 \mathrm{H}), 2.59(\mathrm{~s}$, $6 \mathrm{H}), 3.86(\mathrm{~s}, 2 \mathrm{H}), 4.03(\mathrm{~s}, 2 \mathrm{H}), 6.09(\mathrm{~s}, 2 \mathrm{H}), 7.36-7.40(\mathrm{~m}, 2 \mathrm{H})$, $7.47-7.50(\mathrm{~m}, 5 \mathrm{H}), 7.61(\mathrm{~d}, J=8.2 \mathrm{~Hz}, 1 \mathrm{H}), 7.65(\mathrm{~d}, J=2.4 \mathrm{~Hz}$, $1 \mathrm{H}), 7.70$ (d, $J=8.2 \mathrm{~Hz}, 2 \mathrm{H}), 7.74$ (d, $J=8.8 \mathrm{~Hz}, 2 \mathrm{H}), 8.07$ (d, $J=8.4 \mathrm{~Hz}, 2 \mathrm{H}), 8.53$ (s, 1H) ppm; ${ }^{13} \mathrm{C} \mathrm{NMR}\left(125 \mathrm{MHz}, \mathrm{CDCl}_{3}\right)$ : $\delta=14.75,17.58,42.26,52.20,59.18,122.39,125.29,125.59$, $126.86,127.11,127.88,128.13,128.54,129.63,130.33,131.50$, 131.89, 133.16, 133.41, 136.58, 138.27, 139.01, 139.93, 140.13, 140.46, 142.22, 155.18 ppm (one aromatic carbon signal was not observed owing to overlapping resonances); HRMS (ESI): $m / z(\%):[\mathrm{M}+\mathrm{H}]^{+}$calcd for $\mathrm{C}_{42} \mathrm{H}_{38} \mathrm{~N}_{3} \mathrm{BBrF}_{2}, 712.23047$; found 712.23069 .

1-(4'-(Anthracen-9-yl)-4-(4,4,5,5-tetramethyl-1,3,2-dioxaborolan2-yl)-[1,1'-biphenyl]-3-yl)- $N$-((5,5-difluoro-1,3,7,9-tetramethyl-5H4l4,5l4-dipyrrolo[1,2-c:2' $\left.\mathbf{1}^{\prime}-f\right][1,3,2]$ diazaborinin-10-yl)methyl)- $N$ methylmethanamine (DJ-2). A solution of $4(0.071 \mathrm{~g}, 0.10 \mathrm{mmol})$, bis(pinacolato)diboron (0.041 g, $0.16 \mathrm{mmol}$ ), $\mathrm{PdCl}_{2}(\mathrm{dppf}) \cdot \mathrm{CH}_{2} \mathrm{Cl}_{2}$ (0.009 g, $0.011 \mathrm{mmol})$, and KOAc $(0.031 \mathrm{~g}, 0.32 \mathrm{mmol})$ in 1,4dioxane $(3 \mathrm{~mL})$ was refluxed for $20 \mathrm{~h}$ under a nitrogen atmosphere. After concentrating under reduced pressure, the resulting residue was dissolved in dichloromethane and washed with water. The dichloromethane extract was dried over anhydrous $\mathrm{MgSO}_{4}$, filtrated with Celite, and evaporated under reduced pressure. The residue was dissolved in toluene, and HPLC was performed to give DJ-2 (0.015 g, 19\% yield) as a reddish brown solid; m.p. $147-150{ }^{\circ} \mathrm{C}$; FT-IR (ATR): $\tilde{v}=2972,1544,1508,1344,1305,1193,1157,1072$, $975 \mathrm{~cm}^{-1}$; ${ }^{1} \mathrm{H}$ NMR (500 MHz, $\left.\mathrm{CDCl}_{3}\right): \delta=1.37$ (s, 12H), 2.35 (s, 3H), 2.51 (s, 6H), $2.58(\mathrm{~s}, 6 \mathrm{H}), 3.98(\mathrm{~s}, 2 \mathrm{H}), 4.14(\mathrm{~s}, 2 \mathrm{H}), 6.07$ (s, 2H), 7.17-7.19 (m, 1H), 7.37-7.40 (m, 2H), 7.47-7.51 (m, 4H), $7.63(\mathrm{~d}, J=7.8 \mathrm{~Hz}, 1 \mathrm{H}), 7.73-7.78(\mathrm{~m}, 4 \mathrm{H}), 7.91(\mathrm{~d}, J=7.7 \mathrm{~Hz}$, $1 \mathrm{H}), 8.07$ (d, $J=8.4 \mathrm{~Hz}, 2 \mathrm{H}), 8.52(\mathrm{~s}, 1 \mathrm{H}) \mathrm{ppm} ;{ }^{13} \mathrm{C}$ NMR $\left(125 \mathrm{MHz}, \mathrm{CDCl}_{3}\right): \delta=14.73,17.49,24.73,25.12,41.51,51.86$, $58.47,83.79,122.23,124.70,125.28,125.54,126.78,126.99$, $127.10,127.85,128.51,130.36,131.51,131.80,133.44,136.59$, 136.80, 138.18, 139.96, 141.28, 142.36, 142.93, 145.91, 154.91 ppm (one aromatic carbon signal was not observed owing to overlapping resonances); HRMS (ESI): $m / z(\%):[\mathrm{M}+\mathrm{H}]^{+}$calcd for $\mathrm{C}_{48} \mathrm{H}_{50} \mathrm{O}_{2} \mathrm{~N}_{3} \mathrm{~B}_{2} \mathrm{~F}_{2}$, 760.40517; found 760.40619 .

\section{Conflicts of interest}

There are no conflicts to declare.

\section{Acknowledgements}

This work was supported by a Grant-in-Aid for Scientific Research on Innovative Areas "Soft Crystals" (No. 2903) (JSPS KAKENHI Grant No. 18H04520) and for Scientific Research (B) (JSPS KAKENHI Grant No. 19H02754), and by Nakanishi Scholarship Foundation. 


\section{Notes and references}

1 (a) J. Lee, M. Pyo, S. Lee, J. Kim, M. Ra, W.-Y. Kim, B. J. Park, C. W. Lee and J.-M. Kim, Nat. Commun., 2014, 5, 3736; (b) T. Maeda and F. Würthner, Chem. Commun., 2015, 51, 7661; (c) H. S. Jung, P. Verwilst, W. Y. Kim and J. S. Kim, Chem. Soc. Rev., 2016, 45, 1242; (d) A. Wang, R. Fan, Y. Dong, Y. Song, Y. Zhou, J. Zheng, X. Du, K. Xing and Y. Yang, ACS Appl. Mater. Interfaces, 2017, 9, 15744; (e) M. Tanioka, S. Kamino, A. Muranaka, Y. Shirasaki, Y. Ooyama, M. Ueda, M. Uchiyama, S. Enomoto and D. Sawada, Phys. Chem. Chem. Phys., 2017, 19, 1209; $(f)$ S. Song, Y. Zhang, Y. Yang, C. Wang, Y. Zhou, C. Zhang, Y. Zhao, M. Yang and Q. Lin, Analyst, 2018, 143, 3068; (g) H. Yan, S. Guo, F. Wu, P. Yu, H. Liu, Y. Li and L. Mao, Angew. Chem., Int. Ed., 2018, 57, 3922.

2 (a) Y. Zhou, G. Baryshnikov, X. Li, M. Zhu, H. Ågren and L. Zhu, Chem. Mater., 2018, 30, 8008; (b) P. Kumar, R. Sakla, A. Ghosh and D. A. Jose, ACS Appl. Mater. Interfaces, 2017, 9, 25600; (c) S. Pawar, U. K. Togiti, A. Bhattacharya and A. Nag, ACS Omega, 2019, 4, 11301; (d) F. Wu, L. Wang, H. Tang and D. Cao, Anal. Chem., 2019, 91, 5261; (e) W. Cheng, Y. Xie, Z. Yang, Y. Sun, M.-Z. Zhang, Y. Ding and W. Zhang, Anal. Chem., 2019, 91, 5817.

3 (a) D. Citterio, K. Minamihashi, Y. Kuniyoshi, H. Hisamoto, S. Sasaki and K. Suzuki, Anal. Chem., 2001, 73, 5339; (b) C.-G. Niu, A.-L. Guan, G.-M. Zeng, Y.-G. Liu and Z.-W. Li, Anal. Chim. Acta, 2006, 577, 264; (c) C.-G. Niu, P.-Z. Qin, G.-M. Zeng, X.-Q. Gui and A.-L. Guan, Anal. Bioanal. Chem., 2007, 387, 1067; (d) Z.-Z. Li, C.-G. Niu, G.-M. Zeng and P.-Z. Qin, Chem. Lett., 2009, 38, 698; (e) Z. Li, Q. Yang, R. Chang, G. Ma, M. Chen and W. Zhang, Dyes Pigm., 2011, 88, 307; $(f)$ Y. Zhang, D. Li, Y. Li and J. Yu, Chem. Sci., 2014, 5, 2710; $(g)$ W. Chen, Z. Zhang, X. Li, H. Ågren and J. Su, RSC Adv., 2015, 5, 12191.

4 (a) S. Tsumura, T. Enoki and Y. Ooyama, Chem. Commun., 2018, 54, 10144; (b) T. Enoki and Y. Ooyama, Dalton Trans., 2019, 48, 2086; (c) K. Imato, T. Enoki and Y. Ooyama, RSC Adv., 2019, 9, 31466.

5 (a) Y. Ooyama, M. Sumomogi, T. Nagano, K. Kushimoto, K. Komaguchi, I. Imae and Y. Harima, Org. Biomol. Chem., 2011, 9, 1314; (b) Y. Ooyama, A. Matsugasako, T. Nagano, K. Oka, K. Kushimoto, K. Komaguchi, I. Imae and Y. Harima, J. Photochem. Photobiol., A, 2011, 222, 52.
6 (a) Y. Ooyama, A. Matsugasako, K. Oka, T. Nagano, M. Sumomogi, K. Komaguchi, I. Imae and Y. Harima, Chem. Commun., 2011, 47, 4448; (b) Y. Ooyama, A. Matsugasako, Y. Hagiwara, J. Ohshita and Y. Harima, $R S C A d v$., 2012, 2, 7666; (c) Y. Ooyama, K. Uenaka, A. Matsugasako, Y. Harima and J. Ohshita, RSC Adv., 2013, 3, 23255; (d) Y. Ooyama, K. Furue, K. Uenaka and J. Ohshita, RSC Adv., 2014, 4, 25330; (e) Y. Ooyama, S. Aoyama, K. Furue, K. Uenaka and J. Ohshita, Dyes Pigm., 2015, 123, 248; $(f)$ Y. Ooyama, M. Hato, T. Enoki, S. Aoyama, K. Furue, N. Tsunoji and J. Ohshita, New J. Chem., 2016, 40, 7278; (g) Y. Ooyama, R. Nomura, T. Enoki, R. Sagisaka, N. Tsunoji and J. Ohshita, ChemistrySelect, 2017, 2, 7765; (h) Y. Ooyama, R. Sagisaka, T. Enoki, N. Tsunoji and J. Ohshita, New J. Chem., 2018, 42, 13339.

7 (a) W. Liu, Y. Wang, W. Jin, G. Shen and R. Yu, Anal. Chim. Acta, 1999, 383, 299; (b) H. Mishra, V. Misra, M. S. Mehata, T. C. Pant and H. B. Tripathi, J. Phys. Chem. A, 2004, 108, 2346; (c) A. C. Kumar and A. K. Mishra, Talanta, 2007, 71, 2003.

8 L. Ding, Z. Zhang, X. Li and J. Su, Chem. Commun., 2013, 49, 7319.

9 (a) G. Men, G. Zhang, G. Liang, H. Liu, B. Yang, Y. Pan, Z. Wang and S. Jiang, Analyst, 2013, 138, 2847; (b) G. Men, C. Chen, C. Liang, W. Han and S. Jiang, Analyst, 2015, 140, 5454.

10 (a) Y. Hong, J. W. Y. Lama and B. Z. Tang, Chem. Commun., 2009, 4332; (b) Y. Zhang, D. Li, Y. Li and J. Yu, Chem. Sci., 2014, 5, 2710; (c) J. Mei, N. L. C. Leung, R. T. K. Kwok, J. W. Y. Lam and B. Z. Tang, Chem. Rev., 2015, 115, 11718; (d) Y.-X. Li, X.-F. Yang, J.-L. Miao and G.-X. Sun, J. Phys. Chem. C, 2016, 120, 21722; (e) F. Wu, Li. Wang, H. Tang and D. Cao, Anal. Chem., 2019, 91, 5261.

11 (a) J. Shao, H. Sun, H. Guo, S. Ji, J. Zhao, W. Wu, X. Yuan, C. Zhang and T. D. James, Chem. Sci., 2012, 3, 1049; (b) Z. Ma, Y. Ji, Z. Wang, G. Kuang and X. Jia, J. Mater. Chem. C, 2016, 4, 10914; (c) M. A. Ustimova, A. Yu. Lebedeva, Yu. V. Fedorov, D. V. Berdnikova and O. A. Fedorova, New J. Chem., 2018, 42, 7908; (d) L. Wang, M. Ren, Z. Li, L. Dai and W. Lin, New J. Chem., 2019, 43, 552; (e) G. Zhang, R. Ji, X. Kong, F. Ning, A. Liu, J. Cui and Y. Ge, RSC Adv., 2019, 9, 1147.

12 S. Pal, M. Mukherjee, B. Sen, S. Lohar and P. Chattopadhyay, RSC Adv., 2014, 4, 21608.

13 D. Jinbo, K. Imato and Y. Ooyama, $R S C A d v ., 2019$, 9, 15335. 